\title{
SENSITIVITY AND SPECIFICITY OF A NESTED POLYMERASE CHAIN REACTION FOR DETECTION OF LENTIVIRUS INFECTION IN LIONS (PANTHERA LEO)
}

\author{
Hayley Adams, D.V.M., Ph.D., Dipl. A.C.V.P.M., Moritz van Vuuren, B.V.Sc., M.Med.Vet., \\ Stephen Kania, M.S., Ph.D., Anna-Mari Bosman, M. Tech., Dewald Keet, B.V.Sc., M.Med.Vet., \\ John New, D.V.M., M.P.H., Dipl. A.C.V.P.M., and Melissa Kennedy, D.V.M., Ph.D., Dipl. A.C.V.M.
}

\begin{abstract}
Feline immunodeficiency virus (FIV) is a lentivirus in the Retroviridae family that causes lifelong infection in domestic cats. The lentivirus of African lions (Panthera leo), referred to as FIVple, is endemic in certain lion populations in eastern and southern Africa. Lentivirus infection leads to immunologic dysfunction and immunosuppressive disease in domestic cats; however, little is known about the pathogenic effects of infection in lions, nor about the epidemiologic impact on free-ranging and captive populations. Whole blood and serum samples were collected opportunistically from free-ranging lions in Kruger National Park, Republic of South Africa (RSA). Whole blood and serum samples were also collected from captive wild lions in the RSA. A nested polymerase chain reaction (PCR) assay for detection of FIV was performed on all whole blood samples. In addition, serum samples were tested for cross-reactive antibodies to domestic feline lentivirus antigens and puma lentivirus synthetic envelope peptide antigen. The PCR assay successfully amplified the lion lentivirus from African lions. The relative sensitivity and relative specificity were $79 \%$ and $100 \%$, respectively, and the positive and negative predictive values were $100 \%$ and $67 \%$, respectively. This research represents the first study to compare genetic material with antibody-based methods of lentivirus detection on lions in RSA. Using PCR as an additional diagnostic test for FIV in lions will increase screening sensitivity and will allow viral characterization among circulating isolates and monitoring of changes in the viral epidemiology within geographic regions and populations over time.
\end{abstract}

Key words: Feline immunodeficiency virus, FIVple, lion lentivirus, lion, Panthera leo, PCR.

\section{INTRODUCTION}

Feline immunodeficiency virus (FIV) is a member of the genus Lentivirus in the Retroviridae family and causes a significant lifelong infection in domestic felines (Felis catus). The virus was first discovered in domestic cats with a history of chronic recurrent and opportunistic infections that resembled the human immunodeficiency virus infection. ${ }^{32}$ Infection with lentivirus has also been detected in several nondomestic feline species, including African lion (Panthera leo) populations in eastern and southern Africa. ${ }^{6,7,26,27,33}$ In these populations, the lentivirus has been referred to as FIVple. Feline lentivirus infection leads to immunologic dysfunction and immunosuppressive disease in domestic cats.

From the Department of Comparative Medicine, College of Veterinary Medicine, University of Tennessee, 2407 River Drive, Knoxville, Tennessee 37996, USA (Adams, Kania, New, Kennedy); the Department of Veterinary Tropical Diseases, Faculty of Veterinary Science, University of Pretoria, Private Bag X04, Onderstepoort 0110, South Africa (van Vuuren, Bosman); and the State Veterinary Services, P.O. Box 12, Skukuza, Kruger National Park 1350, South Africa (Keet). Correspondence should be directed to Dr. Adams (haylevet@yahoo.com).
However, little is known about the pathogenic effects of infection or its epidemiologic impact on free-ranging and captive populations of lions.

Current diagnostic methods for detection of lentivirus infection in domestic and nondomestic felines include viral isolation, immunologic tests for virus-specific antibodies or antigens, and molecular tests for viral DNA or RNA. ${ }^{4,10}$ Virus isolation is considered the gold standard (GS) for definitive diagnosis of lentivirus infection. However, it is not the ideal diagnostic method for FIVple because of its labor intensity and the long length of time required for the virus to replicate in culture. Serology is often used to detect infection, but, whereas, serum antibodies to the virus can develop as early as $2 \mathrm{wk}$ after infection in domestic cats, it may take up to 6 mo to $1 \mathrm{yr}$ postinfection to develop detectable levels. , $^{2,35,44}$ In addition, host maternal antibodies may persist in kittens for 6 mo or longer. ${ }^{3}$ Several rapid, sensitive, and specific enzyme-linked immunosorbent assays (ELISA) are widely available for the detection of antibodies to FIV in domestic cats, and two commercial FIV ELISA test kits are licensed by the U.S. Department of Agriculture for use in domestic cats (SNAP ${ }^{\circledR}$ FIV Antibody/FeLV Antigen Combo Test and PetChek FIV Antibody Test Kit, IDEXX Laboratories, Westbrook, Maine 04092, USA). ${ }^{16}$ 


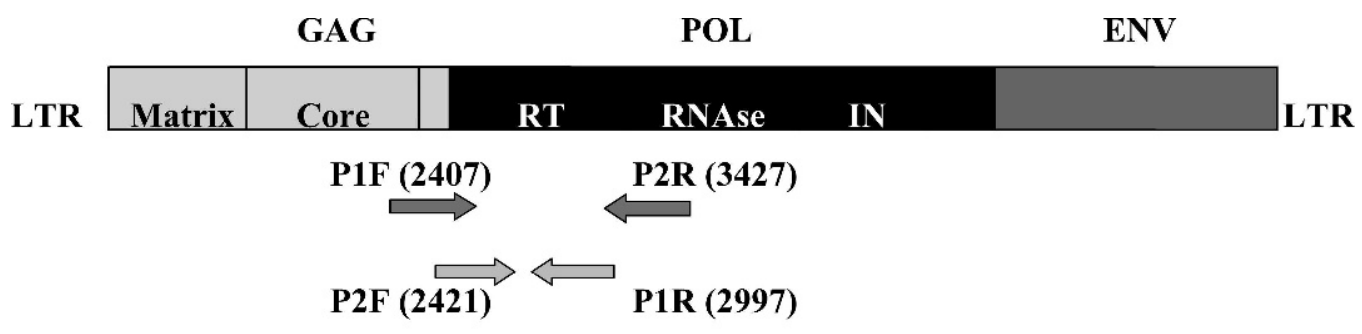

576 BP Product

Figure 1. Schematic representation of the feline immunodeficiency virus genome, including the successful first and second round primers used and their nucleotide position within the reverse transcription region of the Pol gene.

Previous serologic surveys for lentiviruses in nondomestic felids have primarily used domestic cat FIVfca capture antigens. ${ }^{6,8,14,17,27,33}$ Although there is some cross-reactivity between FIVple antigens and FIV antibodies, FIV reagents (particularly monoclonal FIV antibodies) alone may not provide sufficient sensitivity for detection of different subtypes of nondomestic cat lentiviruses. ${ }^{43}$ To increase the sensitivity of serologic testing, species-specific assays have been developed, including a Western blot assay that uses a puma (Felis concolor) lentivirus (FIVpco) cell lysate as the capture antigen and an indirect FIVpco synthetic peptide antigen ELISA with a conserved immunogenic peptide (P237) derived from the envelope (Env) region of the lentivirus genome. ${ }^{20,28-30,38,40-42}$ These assays have been used for lentivirus testing in lions as well as pumas. ${ }^{20,40}$

The various PCR assays available for the detection of viral RNA or proviral DNA present in the host include conventional PCR, nested PCR, quantitative competitive PCR, nucleic acid sequence-based amplification, and real-time PCR. These assays vary significantly in their ability to detect the virus (sensitivity) because of the high nucleotide variability of the virus; thus, no universal PCR exists for the vast number of FIV strains that circulate among domestic and nondomestic felines worldwide. ${ }^{1,5,11,18,19,21-25,31,39}$ Because of the high nucleotide variability of the virus, consensus nondomestic feline lentivirus primers cannot be used to identify all nondomestic cat lentiviruses by PCR, even when permissive annealing conditions are used..$^{43}$ To increase the sensitivity of nucleic acid detection, it is necessary to develop PCRs that are specific to the variety of nondomestic viral strains that are identified in captive and free-roaming felid populations.

The purpose of this investigation was to determine the sensitivity and specificity of a PCR designed to detect the southern African lion lentivirus strains. This nucleic acid-based method of testing was compared with antibody-based methods currently used for testing free-ranging lions in southern Africa and for captive lions in southern Africa and the United States.

\section{MATERIALS AND METHODS}

The samples available for evaluation were collected opportunistically and included 73 whole blood and 63 serum samples from lions in the Kruger National Park (KNP), South Africa, and whole blood and serum samples from 7 lions in The Lion Park, Johannesburg, South Africa. All whole blood and serum samples were stored at $-80^{\circ} \mathrm{C}$ until the time of processing and testing.

\section{DNA extraction}

DNA was extracted from whole blood samples by using the QIAGEN DNeasy Blood and Tissue Extraction kit (Invitrogen, Carlsbad, California 92008, USA), according to the manufacturer's directions, which resulted in $100 \mu \mathrm{l}$ of purified DNA.

\section{Nested PCR}

A nested conventional PCR was performed on the purified DNA by using a protocol developed by Troyer et al., ${ }^{37,38}$ for FIVple and optimized by Dr. H. Adams for use in testing southern African lions. Primers were derived from GenBank published sequence information for FIV (M25381 and U11820), FIVpco (U03982), and FIVoma (Otocolobus manul lentivirus; U56928). ${ }^{37}$ Degenerate primers were developed (Fig. 1) to detect viral DNA from the reverse transcription region of the Pol gene (RT-Pol) of the lentivirus genome, which resulted in a nested 576 base-pair product (including nested primers). The $5^{\prime}$ and $3^{\prime}$ outer primer sequences were TGGCCWYTAWCWAATGAAAARATWGAAGC (referred to as P1F) 
and GTAATTTRTCTTCHGGNGTYTCAAATCCCC (referred to as P2R), respectively. The nested primer sequences were TGAAAARATWGAAGCHTTAACAGAMATAG (referred to as $\mathrm{P} 2 \mathrm{~F}$ ) and GTAATTTRTCTTCHGGNGTYTCAAATCCCC (referred to as P1R), respectively. All primers were synthesized by Sigma Genosys (The Woodlands, Texas 77380, USA) and were reconstituted to a $20 \mathrm{pM}$ working solution.

The nested primer set was used to generate DNA by using Platinum PCR SuperMix (which contained $22 \mathrm{U} / \mathrm{ml}$ complexed recombinant Taq DNA polymerase with Platinum Taq antibody, $22 \mathrm{mM}$ Tris- $\mathrm{HCl}$ at $\mathrm{pH} 8.4,55 \mathrm{mM} \mathrm{KCl}, 1.65 \mathrm{mM}$ $\mathrm{MgCl} 2,220 \mu \mathrm{mol}$ dGTP, dATP, dTTP, and dCTP, and stabilizers [Platinum PCR SuperMix, Invitrogen]). The $54 \mu$ l total volume, first-round PCR reaction mixture consisted of $45 \mu \mathrm{l}$ PCR SuperMix, $2 \mu \mathrm{l}(20 \mathrm{pM})$ of primer P1F, $2 \mu \mathrm{l}$ $(20 \mathrm{pM})$ of primer $\mathrm{P} 2 \mathrm{R}$, and $5 \mu \mathrm{l}$ of sample template. The cycling conditions for the firstround PCR reaction consisted of $3 \mathrm{~min}$ at $94^{\circ} \mathrm{C}$, 45 cycles of $30 \mathrm{sec}$ at $94^{\circ} \mathrm{C}, 30 \mathrm{sec}$ at $52^{\circ} \mathrm{C}$, and $45 \mathrm{sec}$ at $72^{\circ} \mathrm{C}$, with a final extension for $10 \mathrm{~min}$ at $72^{\circ} \mathrm{C}$. Three microliters of the resultant PCR product from round 1 were added to a nested PCR reaction mixture that consisted of $45 \mu 1$ of PCR SuperMix, $1 \mu \mathrm{l}$ of primer P2F, and $1 \mu \mathrm{l}$ of primer P1R, for a total volume per sample of $50 \mu$. The cycling conditions for the nested reactions were the same as for the first-round PCR reaction. All reactions were carried out in an Eppendorf Mastercycler personal PCR thermocycler (Eppendorf, Westbury, New York 11590, USA). Products were analyzed by agarose gel electrophoresis.

\section{PCR DNA purification}

DNA amplicons were extracted from agarose gel by using the QIAGEN QIAquick gel extraction kit (Invitrogen) according to the manufacturer's instructions. All positive PCR products were submitted for molecular sequencing at the University of Tennessee Molecular Biology Resource Facility DNA sequencing laboratory. The primers used for sequencing were $\mathrm{P} 2 \mathrm{~F}$ and $\mathrm{P} 1 \mathrm{R}$, at a 5 pmol solution.

\section{Sequence analysis}

Sequences were confirmed as FIVple by using the National Center for Biotechnology Information Basic Local Alignment Search Tool (BLAST) software program with a search program for highly similar sequences (megablast). Phylogenetic anal- ysis was performed on all sequences obtained by using DNAstar Lasergene software (DNASTAR Inc., Madison, Wisconsin 53705, USA).

\section{FIVpco ELISA}

Serum samples were tested for cross-reactive antibodies with an indirect ELISA by using a synthetic FIVpco peptide (CPFKDICQL, AA 610-618, GenBank U03983) located on the Env glycoprotein, which corresponded to peptide P237 of FIV (CNQNQFFCK). ${ }^{20}$ Prior research with this ELISA demonstrated cross-reactivity to lion lentivirus antigen, presumably with $\operatorname{IgG}$ isotype antibodies. ${ }^{20,40}$

\section{FIV ELISA}

Twenty-five serum samples were tested for crossreactive antibody against FIV gag p24 protein antigens with an ELISA known as the SNAP $^{\circledR}$ Combo FIV Antibody/FeLV antigen test, according to the manufacturer's instructions. Samples from KNP lions were selected by using a random number generator, because budget constraints prevented the testing of all samples in RSA.

\section{Sensitivity and specificity}

Indirect estimates of sensitivity and specificity were calculated according to the recommendations of Thrusfield, which suggest that, when there is no GS, a bank of standard tests is used to compare against the results of the new test. ${ }^{36}$ The FIV ELISA and FIVpco ELISA were used together as the bank of tests to compare with the PCR. If samples tested positive to both tests in the bank, then the sample was classified as positive. If samples tested negative to both tests in the bank, then the sample was classified as negative. All samples with intermediate results (one positive, one negative) were discarded from the calculations. The calculated values were then referred to as the "relative" sensitivity and specificity. However, only 23 samples were tested with all 3 tests (FIV ELISA, FIVpco ELISA, PCR). Of these 23 samples (Table 1), 3 samples gave intermediate results and were thus discarded, which left a sample size of 20 for calculations. The calculations of each value are shown in Table 2.

Because the total number of samples tested with both the FIVpco ELISA and the PCR was higher $(n=67)$ than the number tested with all 3 tests mentioned above (FIV ELISA, FIVpco ELISA, and PCR), an alternative method of calculating sensitivity and specificity was used in 
Table 1. Results of samples tested for feline lentivirus in lions of the Kruger National Park, Republic of South Africa. ${ }^{\mathrm{a}}$

\begin{tabular}{|c|c|c|c|}
\hline Sample ID & $\begin{array}{l}\text { FIVfca } \\
\text { ELISA } \\
\text { (pos/neg) }\end{array}$ & $\begin{array}{c}\text { FIVpco } \\
\text { ELISA } \\
\text { (pos/neg) }\end{array}$ & $\begin{array}{c}\text { UTCVM } \\
\text { PCR (pos/neg) }\end{array}$ \\
\hline E3D00 & Pos & Pos & Pos \\
\hline 550205 & Pos & Pos & Pos \\
\hline $67 \mathrm{~B} 35$ & Pos & Pos & Pos \\
\hline $40085 \mathrm{E}$ & Pos & Pos & Pos \\
\hline 33833 & Pos & Pos & Pos \\
\hline F1F6314 & Pos & Pos & Pos \\
\hline D655B & Pos & Pos & Pos \\
\hline 321408 & Pos & Pos & Pos \\
\hline D184C4C & Pos & Pos & Pos \\
\hline 95270 & Pos & Pos & Pos \\
\hline 249 A $3 A$ & Pos & Pos & Pos \\
\hline 21848 & Neg & Neg & $\mathrm{Neg}$ \\
\hline $\mathrm{B} 2 \mathrm{C} 2 \mathrm{D}$ & $\mathrm{Neg}$ & $\mathrm{Neg}$ & $\mathrm{Neg}$ \\
\hline $5 A 5278$ & Neg & $\mathrm{Neg}$ & $\mathrm{Neg}$ \\
\hline 44 A559AF76 & Neg & Neg & $\mathrm{Neg}$ \\
\hline Bill-LP & Neg & Neg & $\mathrm{Neg}$ \\
\hline Ben-LP & Neg & Neg & $\mathrm{Neg}$ \\
\hline $\mathrm{A} 251 \mathrm{~B}^{\mathrm{b}}$ & Pos & Pos & $\mathrm{Neg}$ \\
\hline $534 \mathrm{E} 04^{\mathrm{b}}$ & Pos & Pos & $\mathrm{Neg}$ \\
\hline B $176607^{b}$ & Pos & Pos & $\mathrm{Neg}$ \\
\hline $\mathrm{C} 4560^{\mathrm{c}}$ & Pos & Neg & Pos \\
\hline $80263^{c}$ & Pos & Neg & Pos \\
\hline $\mathrm{D} 062 \mathrm{~B}^{\mathrm{d}}$ & Pos & Neg & Neg \\
\hline $\mathrm{E} 4223^{\mathrm{e}}$ & Pos & $\mathrm{Neg}$ & $\begin{array}{l}\text { No whole blood } \\
\text { available }\end{array}$ \\
\hline
\end{tabular}

${ }^{a}$ FIV, feline immunodeficiency virus; ELISA, enzyme-linked immunosorbent assay; pos, positive; neg, negative.; PCR, polymerase chain reaction.

${ }^{b}$ Discrepancy between PCR and ELISAs; agreement between FIVfca and FIVpco ELISAs.

${ }^{\mathrm{c}}$ Discrepancy between FIVfca and FIVpco ELISA; PCR agreement with FIVfca ELISA.

${ }^{\mathrm{d}}$ Discrepancy between FIVfca and FIVpco ELISA; PCR agreement with FIVpco ELISA.

${ }^{\mathrm{e}}$ Discrepancy between FIVfca and FIVpco ELISA; no whole blood available for PCR.

Table 2. FIVpco and FIVfca ELISA panel (both positive or both negative) as gold standard (GS). ${ }^{a, b ; 36}$

\begin{tabular}{lccc}
\hline \multicolumn{1}{c}{ PCR } & Positive $(+)$ & Negative $(-)$ & Total \\
\hline Positive $(+)$ & 11 & 0 & 11 \\
Negative $(-)$ & 3 & 6 & 9 \\
Total & 14 & 6 & 20 \\
\hline
\end{tabular}

a Indirect estimates of sensitivity and specificity were calculated according to the recommendations of Thrusfield, ${ }^{36}$ which suggest that, when there is no GS, a bank of standard tests is used to compare against the results of the new test.

${ }^{\mathrm{b}}$ FIV, feline immunodeficiency virus; ELISA, enzyme-linked immunosorbent assay; PCR, polymerase chain reaction.
Table 3. Calculation of PCR sensitivity (sen), specificity (spec), and FIVple prevalence using FIVpco as a reference test in the absence of a true gold standard, and when the true disease state is unknown. ${ }^{34}$ FIVpco (reference test) sensitivity: $85 \%$; specificity: 100\%, from van Vuuren. ${ }^{40}$ There were 67 samples tested with both PCR and FIVpco available for the calculation.

\begin{tabular}{lccc}
\hline \multicolumn{1}{c}{ PCR $_{\text {New }}$} & Positive $(+)$ & Negative $(-)$ & Total \\
\hline Positive $(+)$ & $29_{\mathrm{a}}$ & $4_{\mathrm{b}}$ & $33_{\mathrm{g}}$ \\
Negative $(-)$ & $8_{\mathrm{c}}$ & $26_{\mathrm{d}}$ & $34_{\mathrm{h}}$ \\
Total & $37_{\mathrm{e}}$ & $30_{\mathrm{f}}$ & $67_{\mathrm{n}}$ \\
\hline
\end{tabular}

${ }^{\text {a }} \mathrm{PCR}$, polymerase chain reaction; FIV, feline immunodeficiency virus; ELISA, enzyme-linked immunosorbent assay; pos, positive; neg, negative. Formula used for calculations:

sensitivity $\mathrm{New}=\mathrm{g}\left(\mathrm{spec}_{\text {Reference }}\right)-\mathrm{b} / \mathrm{n}\left(\operatorname{spec}_{\text {Reference }}-1\right)+\mathrm{e}=49 \%$ specificity $_{\text {New }}=\mathrm{h}\left(\operatorname{sen}_{\text {Reference }}\right)-\mathrm{c} / \mathrm{n}\left(\operatorname{sen}_{\text {Reference }}\right)-\mathrm{e}=51 \%$ prevalence $=\mathrm{n}\left(\mathrm{spec}_{\text {Reference }}-1\right)+\mathrm{e} / \mathrm{n}\left(\operatorname{sen}_{\text {Reference }}+\operatorname{spec}_{\text {Reference }}-1\right)$ $=54 \%$

addition to the bank of tests method (Table 3). This alternative method was used for calculations of test sensitivity and specificity when there was no GS available but the sensitivity and specificity of a reference test (FIVpco ELISA) are known. ${ }^{13,34}$

\section{RESULTS}

A total of 77 lions were immobilized and sampled in the KNP during a 2004 census of the lions, and epidemiologic information was recorded on each lion. Of the lions tested during the census (referred to as KNP-Epi), a total of 73 whole blood samples and 63 serum samples were obtained for lentivirus testing. Of the 63 serum samples, all were tested with the FIVpco ELISA; however, only 52 samples were banked in frozen storage and thus available for further antibody testing. Because geographic location was recorded for each animal, the KNP-Epi subset can be further subdivided into the KNP-Epi North (KNP-EPI-N) and KNP-Epi South (KNP-EPI-S) lions.

Whole blood samples from free-ranging and captive lions were tested for FIVple by the University of Tennessee, College of Veterinary Medicine (Knoxville, Tennessee, USA) nested PCR. Of the 80 samples tested with PCR (73 from KNP and 7 from the Lion Park), 44 were positive and 36 were negative for lion lentivirus. Forty-four samples from KNP-Epi lions were positive and 29 were negative of 73 samples tested by PCR. Of the KNP-Epi samples, 9 positives were from the $23 \mathrm{KNP}$ North lions sampled, and 35 positives were from the 50 KNP South lions 
tested. None of the 7 lions tested from the Lion Park were positive by the PCR.

Sequences were checked for degree of genetic homology by using BLAST technology. All KNP sequences amplified from lions were homologous to FIVple, with an average homology identity of $94 \%$.

Thirty-eight of 70 samples ( 63 from KNP and 7 from the Lion Park) tested antibody positive, and 32 tested antibody negative of the serum samples tested by using the FIVpco ELISA. A total of 38 of $63 \mathrm{KNP}$-Epi lion samples were positive: 11 positives were from KNP-Epi-N lions and 27 positives were from KNP-Epi-S lions. None of the Lion Park samples were positive.

Eighteen of 24 serum samples tested by using the FIV ELISA were antibody positive, with the remaining six samples antibody negative. All 18 positives came from KNP-Epi-S lions. No FIV ELISAs were performed on the KNP-Epi-N lions, because no serum samples were available for testing from KNP-Epi-N lions.

There were 23 samples tested by all three tests (FIV ELISA, FIVpco ELISA, PCR) of the 24. Three were eliminated because of the discordant results between the ELISA tests, which left only 20 samples for further calculations (Table 2). The relative PCR sensitivity was $79 \%$, and the relative PCR specificity was $100 \%$ based on the method suggested by Thrusfield. ${ }^{36}$ The positive and negative predictive values for the PCR were calculated to be $100 \%$ and $67 \%$, respectively.

The alternative calculated PCR sensitivity and specificity were $49 \%$ and $51 \%$, respectively, which are significantly lower than the values calculated according to the banked test method $(79 \%$ and $100 \%$, respectively). The prevalence was calculated at $54 \%$, which is similar to the abovementioned calculated prevalence (Table 3 ).

\section{DISCUSSION}

This investigation examined lentivirus infection in convenience samples of southern African lions and, to the authors' knowledge, represents the first descriptive epidemiologic study of FIVple among the lions of the KNP. It is also the first study of this scope that compares detection of viral nucleic acid with antibody-based methods of FIVple testing on lions in RSA.

Feline lentiviruses have a high mutation rate and undergo continual evolution within a host and among a population to escape host immune defense mechanisms. This may lead to a lack of virus detection because of antigenetic or genetic heterogeneity. It is possible that previously published reports of seronegative populations of lions, as well as the seronegative and/or PCRnegative lions identified in this investigation, may be infected with an unidentified subtype of FIVple. Lions in the Serengeti were reported to have multiple subtypes circulating among their population, and some individuals were infected with multiple subtypes. ${ }^{37}$ The lions of KNP may also be infected with multiple subtypes of FIVple, some of which could not be detected with the assays used in this study. The successful PCR primers used in this study were not developed based on sequences obtained from any southern African lions. Thus, they may not be optimal for detecting subtypes of FIVple unique to southern African lions but rather were successful in detecting subtypes shared among lions in eastern Africa, as well as in detecting sequences that may be more conserved among feline lentiviruses. Sequence information may also be useful to develop additional primers for PCR that are more specific to each subtype of FIVple. This may help to increase the overall sensitivity for detecting the virus in a population by increasing the chance of detecting the virus in an individual, regardless of subtype.

Individual hosts can become co-infected or superinfected with multiple FIV types and/or subtypes, and the possibility exists for a new subtype to emerge that may result in a clinical manifestation of disease. PCR is an important tool for monitoring the types and subtypes present, as well as for monitoring the continual evolution of FIVple, because it allows genetic characterization of the isolates.

To calculate the sensitivity of a new diagnostic test, ideally, it should be compared against a GS test, which for most viruses is virus isolation. However, because virus isolation is neither practical nor possible for the purposes of this study, it was necessary to use some of the currently available serologic diagnostic tests for FIVple. Although Bayesian inference or maximum likelihood methods can estimate diagnostic test accuracy when a reference test does not exist, there are other available methods for the estimation of diagnostic test accuracy when a reference test exists that is suboptimal (i.e., no GS). ${ }^{13,15,34}$ The results of one such method to estimate diagnostic test accuracy when a suboptimal reference test exists is shown in Table 3.

The FIVpco ELISA, or puma lentivirus ELISA, as it is also known, was reported to have a sensitivity and specificity of $85 \%$ and $100 \%$, respectively. ${ }^{40}$ These estimates were calculated 
based on testing free-ranging lions in RSA; thus, it is reasonable to assume that the estimates of sensitivity and specificity will hold true for the purposes of this research. This test uses a synthetic FIVpco peptide (CPFKDICQL, AA 610-618, GenBank U03983) that corresponds to an epitope, a highly conserved peptide P237 of FIV, of the Env glycoprotein. IDEXX Laboratories reports a sensitivity and specificity of $100 \%$ and $99.5 \%$, respectively, for the FIV snap test when used on samples from domestic cats. There are no known published studies of the sensitivity and specificity of the FIV ELISA as tested on African lions; thus, FIV ELISA test results of the lion samples must be interpreted with caution. The FIV ELISA uses recombinant gag proteins that are believed to be highly immunogenic, yet conserved among feline lentiviruses. ${ }^{9,12}$ Overall, there was $83 \%$ agreement $(20 / 24)$ between the two forms of antibody testing, with only four discrepant results (Table 1). All four of the discrepant results were positive when using the FIV ELISA and negative when using the FIVpco ELISA. In addition, among these four discrepant results, two were also positive by PCR, one was negative by PCR, and one was not tested with PCR because no whole blood was available for testing. Of the two PCR positives, one was sequenced as FIVple. This indicates that the FIV ELISA positive is true and that the FIVpco ELISA negative was false. Given these results, it is reasonable to assume that the reported FIV ELISA sensitivity of $100 \%$ (in domestic cats) may be extrapolated to a higher sensitivity than that of the FIVpco ELISA when testing lion serum samples with respect to the FIVple isolates circulating among the lions sampled for this investigation. This also indicates that PCR may be more sensitive than the FIVpco ELISA in detecting FIVple among the lions sampled in this investigation.

The development of an antibody response can take several months to a year to develop after infection; thus, antibody detection alone may miss some positives in the early stages of infection. ${ }^{2}$ It is common for wildlife veterinarians and wildlife managers in southern Africa to request feline lentivirus testing before translocating lions or during routine immobilizations. The University of Pretoria's Faculty of Veterinary Science currently uses the FIVpco ELISA as the routine test for diagnosis of FIVple in African lions. Using PCR as an additional diagnostic test for FIV in lions will increase screening sensitivity and may help to identify which types and/or subtypes are circulat- ing among a population of lions. In addition, PCR will be useful when translocations are necessary, to monitor for changes in the viral epidemiology of a region over time.

\section{Future studies}

Much work remains to better characterize the lentiviruses of lions in general and southern African lions in particular. Other regions of the genome could also be sequenced to elucidate potential conservative areas ideal for a more universal PCR, as well as to develop a PCR to specifically detect FIVple. The development of a real-time PCR assay would allow for the monitoring of viral subtype(s), viral load, and shedding patterns among individual free-ranging or captive FIVple positive lions.

Acknowledgments: The authors thanks Dr. Kathy Thomas, Clinical Virology Diagnostic Service, and to Dianne Trent, Clinical Immunology Diagnostic Service, the Department of Comparative Medicine, The University of Tennessee; and Sandra Prinsloo, Serology Laboratory, Department of Veterinary Tropical Diseases, The University of Pretoria, for laboratory assistance. Samples from free-ranging lions were provided courtesy of the veterinary staff of South African National Parks-Kruger National Park Services. Samples from captive animals were provided courtesy of the Lion Park, Johannesburg. In addition, the authors thank Misty R. Bailey, A.S., B.A., M.A., E.L.S., technical communication specialist, College of Veterinary Medicine, University of Tennessee, for assistance with manuscript editing, and to Anik Vasington, for assistance with figure editing. Funding was provided by the Center of Excellence in Livestock Diseases and Human Health and the Department of Comparative Medicine College of Veterinary Medicine, University of Tennessee. Funding for sample collection and storage in South Africa was provided courtesy of the South Africa Veterinary Foundation.

\section{LITERATURE CITED}

1. Arjona, A., N. Barquero, A. Doménech, G. Tejerizo, V. Collado, C. Toural, D. Martin, and E. Gomez-Lucia. 2006. Evaluation of a novel nested PCR for the routine diagnosis of feline leukemia virus (FeLV) and feline immunodeficiency virus (FIV). J. Feline Med. Surg. 9: 14-22.

2. Barr, M. 1996. FIV, FeLV, and FIPV: interpretation and misinterpretation of serological test results. Semin. Vet. Med. Surg. (Small Anim.). 11: 144-153. 
3. Barr, M., M. Pough, R. Jacobson, and F. Scott 1991. Comparison and interpretation of diagnostic tests for feline immunodeficiency virus infection. J. Am. Vet. Med. Assoc. 199: 1377-1381.

4. Bendinelli, M., M. Pistello, S. Lombardi, A. Poli, C. Garzelli, D. Matteucci, L. Ceccherini-Nelli, G. Malvaldi, and F. Tozzini. 1995. Feline immunodeficiency virus: an interesting model for AIDS studies and an important cat pathogen. Clin. Microbiol. Rev. 8: 87112.

5. Bisset, L., S. Bosbach, Z. Tomasik, H. Lutz, J. Schüpbach, and J. Böni. 2001. Quantification of in vitro retroviral replication using a one-tube real-time RT-PCR system incorporating direct RNA preparation. J. Virol. Methods. 91: 149-155.

6. Brown, E., N. Yuhki, C. Packer, and S. O'Brien. 1994. A lion lentivirus related to feline immunodeficiency virus: epidemiologic and phylogenetic aspects. J. Virol. 68: 5953-5968.

7. Burkhard, M., and G. Dean. 2003. Transmission and immunopathogenesis of FIV in cats as a model for HIV. Curr. HIV Res. 1: 15-29.

8. Carpenter, M., E. Brown, M. Culver, W. Johnson, J. Pecon-Slattery, D. Brousset, and S. O'Brien. 1996. Genetic and phylogenetic divergence of feline immunodeficiency virus in the puma (Puma concolor). J. Virol. 70: 6682-6693.

9. Coffin, J. 1986. Genetic variation in AIDS viruses. Cell. 46: 1-4.

10. Crawford, P., and J. Levy. 2007. New challenges for the diagnosis of feline immunodeficiency virus infection. Vet. Clin. North Am. Small Anim. Pract. 37: 335-350, vii.

11. Crawford, P., M. Slater, and J. Levy. 2005. Accuracy of polymerase chain reaction assays for diagnosis of feline immunodeficiency virus infection in cats. J. Am. Vet. Med. Assoc. 226: 1503-1507.

12. Dowbenko D., J. Bell, C. Benton, J. Groopman, H. Nguyen, D. Vetterlein, D. Capon, and L. Lasky. 1985. Bacterial expression of the acquired immunodeficiency syndrome retrovirus p24 gag protein and its use as a diagnostic reagent. Proc. Nat. Acad. Sci. USA. 82: 7748-7752.

13. Enoe, C., M. Georgiadis, and W. Johnson. 2000. Estimation of sensitivity and specificity of diagnostic tests and disease prevalence when the true disease state is unknown. Prev. Vet. Med. 45: 61-81.

14. Evermann, J., W. Foreyt, B. Hall, and A. McKeirnan. 1997. Occurrence of puma lentivirus infection in cougars from Washington. J. Wildl. Dis. 33: $316-320$.

15. Gart, J., and A. Buck. 1966. Comparison of a screening test and a reference test in epidemiologic studies. II. A probabilistic model for the comparison of diagnostic tests. Am. J. Epidemiol. 63: 593-602.

16. Hartmann, K., R. Werner, H. Egberink, and O. Jarrett. 2001. Comparison of six in-house tests for the rapid diagnosis of feline immunodeficiency and feline leukaemia virus infections. Vet. Rec. 149: 317320 .
17. Hofmann-Lehmann, R., D. Fehr, M. Grob, M. Elgizoli, C. Packer, J. Martenson, S. O'Brien, and H. Lutz. 1996. Prevalence of antibodies to feline parvovirus, calicivirus, herpesvirus, coronavirus, and immunodeficiency virus and of feline leukemia virus antigen and the interrelationship of these viral infections in free-ranging lions in east Africa. Clin. Diagn. Lab. Immunol. 3: 554-562.

18. Hohdatsu, T., T. Sasagawa, A. Yamazaki, K. Motokawa, H. Kusuhara, T. Kaneshima, H. Koyama. 2002. CD8+ T cells from feline immunodeficiency virus (FIV) infected cats suppress exogenous FIV replication of their peripheral blood mononuclear cells in vitro. Arch. Virol. 147: 1517-1529.

19. Jordan, H. L., L. A. Scappino, M. Moscardini, and M. Pistello. 2002. Detection of feline immunodeficiency virus RNA by two nucleic acid sequence based amplification (NASBA) formats. J. Virol. Meth. 103: $1-13$.

20. Kania, S., M. Kennedy, and L. Potgieter. 1997. Serologic reactivity using conserved envelope epitopes in feline lentivirus-infected felids. J. Vet. Diagn. Invest. 9: $125-129$.

21. Kipar, A, F. Boretti, M. Meli, K. Failing, M. Reinacher, and H. Lutz. 2004. Reduced constitutive cytokine transcription in isolated monocytes of clinically healthy cats, infected with an FIV strain of low pathogenicity. Vet. Immunol. Immunopathol. 98: 215221.

22. Klein, D., C. Leutenegger, C. Bahula, P. Gold, R. Hofmann-Lehmann, B. Salmons, H. Lutz, and W. Gunzburg. 2001. Influence of preassay and sequence variations on viral load determination by a multiplex real-time reverse transcriptase-polymerase chain reaction for feline immunodeficiency virus. J. Acquir. Immune Defic. Syndr. 26: 8-20.

23. Lawson, M, J. Meers, L. Blechynden, W. Robinson, W. Greene, and P. Carnegie. 1993. The detection and quantification of feline immunodeficiency provirus in peripheral blood mononuclear cells using the polymerase chain reaction. Vet. Microbiol. 38: 11-21.

24. Lee, I., J. Levy, S. Gorman, P. Crawford, and M. Slater. 2002. Prevalence of feline leukemia virus infection and serum antibodies against feline immunodeficiency virus in unowned free-roaming cats. J. Am. Vet. Med. Assoc. 220: 620-622.

25. Leutenegger, C., D. Klein, R. Hofmann-Lehmann, C. Mislin, U. Hummel, J. Boni, F. Boretti, W. Guenzburg, and H. Lutz. 1999. Rapid feline immunodeficiency virus provirus quantitation by polymerase chain reaction using the TaqMan fluorogenic real-time detection system. J. Virol. Methods. 78: 105-116.

26. Lutz, H., E. Isenbügel, R. Lehmann, R. Sabapara, and C. Wolfensberger. 1992. Retrovirus infections in non-domestic felids: serological studies and attempts to isolate a lentivirus. Vet. Immunol. Immunopathol. 35: 215-224.

27. Olmsted, R., R. Langley, M. Roelke, R. Goeken, D. Adger-Johnson, J. Goff, J. Albert, C. Packer, M. 
Laurenson, and T. Caro. 1992. Worldwide prevalence of lentivirus infection in wild feline species: epidemiologic and phylogenetic aspects. J. Virol. 66: 6008-6018.

28. Osofsky, S., K. Hirsch, E. Zuckerman, and W. Hardy. 1996. Feline lentivirus and feline oncovirus status of free-ranging lions (Panthera leo), leopards (Panthera pardus), and cheetahs (Acinonyx jubatus) in Botswana: a regional perspective. J. Zoo Wildl. Med. 27: 453-467.

29. Pancino, G., C. Chappey, W. Saurin, and P. Sonigo. 1993. B epitopes and selection pressures in feline immunodeficiency virus envelope glycoproteins. J. Virol. 67: 664-672.

30. Pancino, G., I. Fossati, C. Chappey, S. Castelot, B. Hurtrel, A. Moraillon, D. Klatzmann, and P. Sonigo. 1993. Structure and variations of feline immunodeficiency virus envelope glycoproteins. Virology. 192: 659662.

31. Pedersen, N., C. Leutenegger, J. Woo, and J. Higgins. 2001. Virulence differences between two field isolates of feline immunodeficiency virus (FIVAPetaluma and FIV-CPGammar) in young adult specific pathogen free cats. Vet. Immunol. Immunopathol. 79: 53-67.

32. Pedersen, N. C., E. W. Ho, M. L. Brown, and J. K. Yamamoto. 1987. Isolation of a T-lymphotropic virus from domestic cats with an immunodeficiency-like syndrome. Science. 235: 790-793.

33. Spencer, J., A. Van Dijk, M. Horzinek, H. Egberink, R. Bengis, D. Keet, S. Morikawa, and D. Bishop. 1992. Incidence of feline immunodeficiency virus reactive antibodies in free-ranging lions of the Kruger National Park and the Etosha National Park in southern Africa detected by recombinant FIV p24 antigen. Onderstepoort J. Vet. Res. 59: 315-322.

34. Staquet, M., M. Rozencweig, Y. Lee, and F. Muggia. 1981. Methodology for the assessment of new dichotomous diagnostic tests. J. Chronic Dis. 34: 599610 .

35. Swango, L. 1991. Evaluation of feline leukemia virus diagnostic tests available for in-office use by veterinarians. J. Am. Vet. Med. Assoc. 199: 1386-1389.

36. Thrusfield, M. 2007. Veterinary Epidemiology. Blackwell Publishing, Ames, Iowa. Pp. 313-318.

37. Troyer, J., J. Pecon-Slattery, M. Roelke, L. Black, C. Packer, and S. O'Brien. 2004. Patterns of feline immunodeficiency virus multiple infection and genome divergence in a free-ranging population of African lions. J. Virol. 78: 3777-3791.

38. Troyer, J., J. Pecon-Slattery, M. Roelke, W. Johnson, S. VandeWoude, N. Vazquez M. Brown, L. Frank, R. Woodroffe, C. Winterbach, H. Winterbach, G. Hemson, M. Bush, K. Alexander, E. Revilla, and S. O'Brien. 2005. Seroprevalence and genomic divergence of circulating strains of feline immunodeficiency virus among Felidae and Hyaenidae species. J. Virol. 79: 8282-8294.

39. Vahlenkamp, T., A. De Ronde, J. Balzarini, L. Naesens, E. De Clercq, M. van Eijk, M. Horzinek, and H. Egberink. 1995. (R)-9-(2-phosphonylmethoxypropyl)-2,6-diaminopurine is a potent inhibitor of feline immunodeficiency virus infection. Antimicrob. Agents Chemother. 39: 746-749.

40. Van Vuuren, M., E. Stylianides, S. Kania, E. Zuckerman, and W. J. Hardy. 2003. Evaluation of an indirect enzyme-linked immunosorbent assay for the detection of feline lentivirus-reactive antibodies in wild felids, employing a puma lentivirus-derived synthetic peptide antigen. Onderstepoort J. Vet. Res. 70: 1-6.

41. VandeWoude, S., C. Hageman, and E. Hoover. 2003. Domestic cats infected with lion or puma lentivirus develop anti-feline immunodeficiency virus immune responses. J. Acquir. Immune Defic. Syndr. 34: 20-31.

42. VandeWoude, S., C. Hageman, S. O'Brien, and E. Hoover. 2002. Nonpathogenic lion and puma lentiviruses impart resistance to superinfection by virulent feline immunodeficiency virus. J. Acquir. Immune Defic. Syndr. 29: 1-10.

43. VandeWoude, S., S. O'Brien, K. Langelier, W. Hardy, J. Slattery, E. Zuckerman, and E. Hoover. 1997. Growth of lion and puma lentiviruses in domestic cat cells and comparisons with FIV. Virology. 233: 185192.

44. Yamamoto, J., E. Sparger, E. Ho, P. Anderson, T. O'Connor, C. Mandell, L. Lowenstine, R. Munn, N. Pedersen. 1988. Pathogenesis of experimentally induced feline immunodeficiency virus infection in cats. Am. J. Vet. Res. 49: 1246-1258.

Received for publication 21 July 2009 